\title{
Sedimentological architecture, shelf-edge trajectories and evolution of an Oligocene reservoir, East Nile Delta - CORRIGENDUM
}

\author{
S. S. SELIM \\ doi: 10.1017/S0016756816000522. Published online by Cambridge University Press, 5 August 2016. \\ The author apologizes that the FirstView publication of this article (Selim, 2016) included a figure (Fig. 12) for \\ which permission had not been granted by the owners, Dana Gas PJSC. \\ The article has been recast, replacing the original Fig. 12 with a new version.
}

